\title{
Percepção dos concluintes sobre a qualidade do curso noturno de Odontologia em instituição pública do nordeste brasileiro
}

\author{
Maria da Conceição do Nascimento*, Patrícia Maria de Ribeiro Vieira**, Fabiana Menezes Teixeira \\ de Carvalho $^{* * *}$, Manoela Almeida Santos da Figueira ${ }^{* * * *}$, Gustavo Pina Godoy******
}

* Egressa, Curso de Odontologia, Universidade Federal de Pernambuco

** Mestranda, Programa de Pós-Graduação em Odontologia, Universidade Federal de Pernambuco

*** Doutoranda, Programa de Pós-Graduação em Odontologia, Universidade Federal de Pernambuco

**** Preceptora/pesquisadora, Instituto de Medicina Integral Prof. Fernando Figueira

***** Professor Doutor, Programa de Pós-graduação em Odontologia, Universidade Federal de Pernambuco

Recebido em 31/03/2020. Aprovado em 03/10/2020.

\begin{abstract}
RESUMO
O presente estudo objetivou avaliar a percepção de concluintes sobre a qualidade do curso noturno de uma instituição de ensino superior (IES), sediada em uma capital do Nordeste do Brasil, por meio das respostas ao questionário do estudante do Enade 2016. Tratou-se de uma pesquisa documental, cujos dados foram obtidos da planilha de microdados do Enade 2016, empregando o código da IES obtido no sistema eletrônico do Ministério da Educação (eMEC). As variáveis sociodemográficas foram utilizadas para caracterizar o perfil dos concluintes. As respostas foram agrupadas em positiva, neutra ou negativa para três seções do questionário: organização didático-pedagógica, infraestrutura/instalações físicas do curso e ampliação da formação acadêmica-profissional. Os testes Qui-quadrado e Exato de Fisher, aplicados com 95\% de confiança, foram utilizados para comparar as respostas dos cursos integral e noturno. O perfil sociodemográfico incluiu um grupo majoritariamente do sexo masculino, idade média de 28,9 anos, solteiros e brancos. Na avaliação da qualidade quanto à organização didático-pedagógica e infraestrutura/instalações físicas do curso, a percepção dos estudantes foi positiva para a maioria dos subcomponentes do questionário. A percepção dos egressos desse curso apresentou resultados positivos, caracterizando indicador de qualidade. Houve diferença estatisticamente significativa nas respostas dos estudantes do curso integral e noturno referentes às oportunidades de extensão, intercâmbios e/ou estágio internacional. $\mathrm{O}$ estudo indicou que este curso noturno não apresenta a mesma percepção de referencial de qualidade, pelos estudantes, quanto às atividades extracurriculares para formação profissional.
\end{abstract}

Descritores: Educação em Odontologia. Educação Superior. Avaliação Educacional. 


\section{INTRODUÇÃO}

A abertura dos cursos noturnos de nível superior no Brasil surgiu da conquista de pressões populares que exigiam o direito à educação nos anos de 1960. No entanto, apenas em 1996, com a lei n. ${ }^{\circ} 394$ - lei de Diretrizes e Bases da Educação Nacional - foi regulamentada a oferta desses cursos nas instituições de ensino superior (IES) públicas, permitindo acesso de estudantes trabalhadores ${ }^{1}$.

$\mathrm{O}$ aumento do número de vagas oferecidas no turno da noite em IES privadas permitiu às classes sociais menos abastadas o acesso ao nível superior de ensino. Essas IES são responsáveis por abrigar a maioria dos estudantes, que mesmo trabalhando até 40 horas semanais, encontram no curso noturno a possibilidade da continuação dos estudos $^{2}$. Nesse cenário, o Ministério da Educação, por meio do Decreto n. ${ }^{0}$ 6.096, de 24 de abril de 2007, instituiu o Programa de Apoio ao Plano de Reestruturação e Expansão das Universidades Federais (REUNI). Esse programa visa o investimento das IES federais em sentido mais amplo, permitindo o aumento de vagas de ingresso e a oferta de ensino, pesquisa e extensão de qualidade para todos. Os principais objetivos são diminuir as desigualdades sociais e promover a inclusão da população menos favorecida ${ }^{3,4}$. No entanto, ainda há uma longa trajetória para atender esses estudantes com igualdade social, respeitando suas especificidades pedagógicas e proporcionando-lhes melhor aproveitamento dos serviços administrativos, de pesquisa e de extensão $0^{1,5}$.

O Exame Nacional de Desempenho de Estudantes (Enade), que integra o Sistema Nacional de Avaliação do Ensino Superior (Sinaes), avalia o processo de aprendizagem e desempenho dos estudantes em relação aos conteúdos programáticos previstos nas diretrizes curriculares do curso. Os dados do questionário do estudante possibilitam a análise do perfil socioeconômico e cultural dos discentes, a percepção do ensino-aprendizagem, da organização do curso, do currículo e da atividade docente $^{6,7}$.

Diante desse novo cenário de formação acadêmica em IES públicas no Brasil, faz-se importante analisar os impactos do processo de expansão sobre a qualidade dos cursos e a formação desses novos profissionais. A presente pesquisa avaliou a percepção da qualidade dos cursos integral e noturno de Odontologia de uma IES pública sediada em uma capital do Nordeste do Brasil, utilizando os dados do questionário do estudante no Enade 2016, a fim de contribuir para os debates relacionados à ampliação dos cursos superiores noturnos e aos impactos desse contexto no progresso da formação profissional em Odontologia.

\section{METODOLOGIA}

Trata-se de estudo documental utilizando o banco de dados do Enade 2016, cuja planilha de microdados foi obtida do site do Instituto Nacional de Estudos e Pesquisas Educacionais Anísio Teixeira (INEP). Dos microdados se extraíram as respostas dadas pelos 126 concluintes do curso de Odontologia de ambos os turnos de uma IES pública sediada em uma capital do nordeste brasileiro.

O questionário do estudante do Enade apresenta 68 questões. O bloco inicial trata do perfil socioeconômico e cultural do estudante com 26 questões de múltipla escolha, organizadas em ordem alfabética.

O segundo bloco contém 42 questões divididas em três componentes (organização didático-pedagógica, infraestrutura/instalações físicas e oportunidade de ampliação da formação acadêmica-profissional). Para cada assertiva deve ser indicado o grau de concordância em uma escala que varia de 1 (discordância total) a 6 (concordância total). Se julgar não ter elementos para avaliar a questão ou considerá-la não 
pertinente ao seu curso, existem as opções ' "não sei responder" e "não se aplica", respectivamente.

Para o estudo foram selecionadas 10 questões do primeiro bloco $(1,2,4,5,8,10,15,17$, $18,23)$, as quais foram reorganizadas em grupos. Nas questões referentes à organização didáticopedagógica (27 à 40, 42, 47 à 50, 51, 55, 57 e 66), infraestrutura e instalações físicas (41, 54, 56, 58, 59 a 65 e 68) e oportunidade de ampliação da formação acadêmica e profissional (43 à 46, 52, 53 e 67), as respostas foram agrupadas conforme o grau de concordância do estudante para cada assertiva. Considerou-se como posição negativa o grupo de respostas variando entre 1 e 2 ; posição neutra, o grupo de respostas variando entre 3, 4 e 7; e posição positiva, as respostas entre 5 e 6 . As respostas 8 (não se aplica) não foram categorizadas.

Os dados coletados foram, posteriormente, sujeitos à análise descritiva com distribuição de percentual. As informações foram analisadas utilizando o software SPSS $® 13.0$ (IBM, Armonk, NY, EUA) para Windows, aplicando-se 95\% de confiança em todos os testes. Para verificar a existência de associação, utilizou-se o teste QuiQuadrado e para as variáveis categóricas, o teste Exato de Fisher. Os resultados foram apresentados em tabela com as respectivas frequências absoluta e relativa.

\section{RESULTADOS}

O questionário do estudante do Enade 2016 foi respondido por 126 concluintes da IES em apreciação, sendo 94 do curso integral e 32 do curso noturno.

O perfil sociodemográfico dos estudantes do curso noturno incluiu um grupo majoritariamente do sexo masculino, com média de idade de $28,9 \pm 6,08$ anos, solteiros e brancos (conforme raça autodeclarada). Destacou-se ainda que $2(37,5 \%)$ estudantes trabalham e sustentam a família; 16
(50\%) possuem renda familiar de 3 a 10 salários mínimos; a maioria (17 - 53,1\%) é proveniente de escola privada, ao passo que $14(43,8 \%)$ estudantes do noturno cursaram o ensino médio em escola pública; e o nível de escolaridade dos pais foi até o ensino médio (tabela 1).

$\mathrm{Na}$ avaliação da qualidade quanto à organização didático-pedagógica e infraestrutura/ instalações físicas do curso, a percepção dos estudantes foi positiva para a maioria dos subcomponentes (tabelas 2 e 3 ).

Ainda sobre esses aspectos, dos 23 itens que compõem a categoria de organização didáticopedagógica, 21 (91\%) tiveram a percepção positiva e apenas 2 foram avaliados de forma neutra: "Foram oferecidas oportunidades para os estudantes superarem dificuldades relacionadas ao processo de formação" $(43,8 \%)$ e "As atividades práticas foram suficientes para relacionar os conteúdos do curso com a prática, contribuindo para sua formação profissional" (46,9\%) (tabela 2).

Com relação aos 12 componentes sobre infraestrutura/instalações físicas, $46,9 \%$ dos estudantes tiveram a percepção neutra quanto ao item "Os ambientes e equipamentos destinados às aulas práticas foram adequados ao curso", $34,4 \%$ tiveram posição negativa quanto ao item "Os equipamentos e materiais disponíveis para as aulas práticas foram adequados para a quantidade de estudantes" e menos de 50\% (46,9\%) consideraram como positiva a disposição de refeitório, cantina e banheiros em condições adequadas que atenderam as necessidades dos seus usuários (tabela 3)

Ao analisar comparativamente os egressos dos cursos integral e noturno da mesma IES, quanto às oportunidades de ampliação da formação acadêmica e profissional, foi possível observar que houve diferença estatisticamente significativa em apenas duas variáveis, de um total de 7 , que constituem esta seção do questionário (tabela 4). 
Tabela 1. Caracterização dos estudantes dos cursos integral e noturno de Odontologia de uma instituição pública em uma capital do nordeste brasileiro quanto aos fatores sociodemográficos

\begin{tabular}{|c|c|c|}
\hline Variáveis & $\begin{array}{c}\text { Curso } \\
\text { Integral } \\
\text { n }(\%) \\
\end{array}$ & $\begin{array}{c}\text { Curso } \\
\text { Noturno } \\
\text { n }(\%) \\
\end{array}$ \\
\hline \multicolumn{3}{|l|}{ Sexo } \\
\hline Masculino & $24(25,5)$ & $18(56,0)$ \\
\hline Feminino & $70(74,5)$ & $14(44,0)$ \\
\hline \multicolumn{3}{|l|}{ Idade } \\
\hline De 21 a 30 & $90(96,0 \%)$ & $22(68,8)$ \\
\hline De 31 a 40 & $4(4,0 \%)$ & $9(28,1)$ \\
\hline Acima de 40 anos & - & $1(3,1)$ \\
\hline \multicolumn{3}{|l|}{ Estado civil } \\
\hline Solteiro & $86(91,5)$ & $28(87,5)$ \\
\hline Casado & $7(7,4)$ & $3(9,4)$ \\
\hline Outros & $1(1,1)$ & $1(3,1)$ \\
\hline \multicolumn{3}{|l|}{ Raça } \\
\hline Branca & $52(55,3)$ & $14(44,0)$ \\
\hline Preta & $4(4,3)$ & $4(13,0)$ \\
\hline Parda & $32(34,0)$ & $11(34,0)$ \\
\hline Outros & $4(4,3)$ & $1(3,0)$ \\
\hline Não quero declarar & $2(2,1)$ & $2(6,0)$ \\
\hline \multicolumn{3}{|l|}{ Renda Familiar } \\
\hline De 1,5 salário até 3 salários & $24(25,5)$ & $13(41,0)$ \\
\hline Mais de 3 salários até 10 salários & $54(57,4)$ & $16(50,0)$ \\
\hline De 10 salários a 30 salários & $15(16,0)$ & $3(9,0)$ \\
\hline Acima de 30 salários & $1(1,1)$ & - \\
\hline \multicolumn{3}{|l|}{ Situação de Trabalho } \\
\hline Não trabalha / Trabalha eventualmente & $93(97,9)$ & $20(62,5)$ \\
\hline 20 ou mais horas de trabalho por semana & $2(2,1)$ & $12(37,5)$ \\
\hline \multicolumn{3}{|l|}{ Tipo de escola que cursou no ensino médio } \\
\hline Todo em escola pública & $19(20,2)$ & $14(44,0)$ \\
\hline Todo em escola privada & $72(76,6)$ & $17(53,0)$ \\
\hline A maior parte em escola privada & $3(3,2)$ & $1(3,0)$ \\
\hline \multicolumn{3}{|l|}{ Ingresso por meio de políticas de ação afirmativa ou inclusão social } \\
\hline Não & $79(84,0)$ & $19(59,4)$ \\
\hline Sim, por critério étnico-racial & - & $1(3,1)$ \\
\hline Sim, por ter estudado em escola pública ou particular com bolsa & $14(14,9)$ & $11(34,4)$ \\
\hline Sim, por sistema que combina dois ou mais critérios & $1(1,1)$ & $1(3,1)$ \\
\hline \multicolumn{3}{|l|}{ Nivel de escolaridade da mãe } \\
\hline Escolaridade inferior ao ensino superior & $40(42,6)$ & $18(56,0)$ \\
\hline Ensino superior & $27(28,7)$ & $8(25,0)$ \\
\hline Pós-graduação & $27(28,7)$ & $6(19,0)$ \\
\hline \multicolumn{3}{|l|}{ Nivel de escolaridade do pai } \\
\hline Escolaridade inferior ao ensino superior & $55(58,5)$ & $21(65,6)$ \\
\hline Ensino superior & $27(28,7)$ & $8(25,0)$ \\
\hline Pós-graduação & $12(12,8)$ & $3(9,4)$ \\
\hline \multicolumn{3}{|l|}{ Horas semanais de dedicação aos estudos } \\
\hline De 1 a 3 horas & $38(40,4)$ & $13(41,0)$ \\
\hline De 4 a 7 horas & $4143,6)$ & $11(34,0)$ \\
\hline De 8 a 12 horas & $12(12,8)$ & $6(19,0)$ \\
\hline Mais de 12 horas & $3(3,2)$ & $2(6,0)$ \\
\hline
\end{tabular}


Tabela 2. Percepção dos estudantes do curso noturno de Odontologia, de uma instituição pública em uma capital do nordeste brasileiro, no tocante à Organização didático-pedagógica

\begin{tabular}{|c|c|c|c|}
\hline \multirow[b]{2}{*}{ Variáveis } & \multicolumn{3}{|c|}{ Resposta } \\
\hline & $\begin{array}{l}\text { Negativa } \\
\text { n }(\%)\end{array}$ & $\begin{array}{l}\text { Neutra } \\
\text { n }(\%)\end{array}$ & $\begin{array}{c}\text { Positiva } \\
\text { n }(\%)\end{array}$ \\
\hline $\begin{array}{l}\text { As disciplinas cursadas contribuíram para sua formação integral, como } \\
\text { cidadão e profissional. }\end{array}$ & - & $6(19,0)$ & $26(81,0)$ \\
\hline $\begin{array}{l}\text { Os conteúdos abordados nas disciplinas do curso favoreceram sua atuação } \\
\text { em estágios ou em atividades de iniciação profissional. }\end{array}$ & - & $7(22,0)$ & $25(78,0)$ \\
\hline $\begin{array}{l}\text { As metodologias de ensino utilizadas no curso desafiaram você a } \\
\text { aprofundar conhecimentos e desenvolver competências reflexivas e } \\
\text { críticas. }\end{array}$ & $2(6,0)$ & $11(34,5)$ & $19(59,5)$ \\
\hline O curso propiciou experiências de aprendizagem inovadoras. & $3(9,0)$ & $13(41,0)$ & $16(50,0)$ \\
\hline $\begin{array}{l}\text { O curso contribuiu para o desenvolvimento da sua consciência ética para } \\
\text { o exercício profissional. }\end{array}$ & - & $6(19,0)$ & $26(81,0)$ \\
\hline No curso você teve oportunidade de aprender a trabalhar em equipe. & $1(3,1)$ & $3(9,4)$ & $28(87,5)$ \\
\hline O curso possibilitou aumentar sua capacidade de reflexão e argumentação. & $2(6,0)$ & $6(19,0)$ & $24(75,0)$ \\
\hline $\begin{array}{l}\text { O curso promoveu o desenvolvimento da sua capacidade de pensar } \\
\text { criticamente, analisar e refletir sobre soluções para problemas da } \\
\text { sociedade. }\end{array}$ & 2 & $, 0)$ & 24( \\
\hline $\begin{array}{l}\text { O curso contribuiu para você ampliar sua capacidade de comunicação nas } \\
\text { formas oral e escrita. }\end{array}$ & $3(9,4)$ & $9(28,1)$ & $20(62,5)$ \\
\hline $\begin{array}{l}\text { O curso contribuiu para o desenvolvimento da sua capacidade de aprender } \\
\text { e atualizar-se permanentemente. }\end{array}$ & $1(3,1)$ & $5(15,6)$ & $26(81,3)$ \\
\hline $\begin{array}{l}\text { As relações professor-aluno ao longo do curso estimularam você a estudar } \\
\text { e aprender. }\end{array}$ & $4(12,0)$ & $6(19,0)$ & $22(69,0)$ \\
\hline $\begin{array}{l}\text { Os planos de ensino apresentados pelos professores contribuíram para o } \\
\text { desenvolvimento das atividades acadêmicas e para seus estudos. }\end{array}$ & $2(6,3)$ & $9(28,1)$ & $21(65,6)$ \\
\hline $\begin{array}{l}\text { As referências bibliográficas indicadas pelos professores nos planos de } \\
\text { ensino contribuíram para seus estudos e aprendizagens. }\end{array}$ & $1(3,1)$ & $9(28,1)$ & $22(68,8)$ \\
\hline $\begin{array}{l}\text { Foram oferecidas oportunidades para os estudantes superarem } \\
\text { dificuldades relacionadas ao processo de formação. }\end{array}$ & $6(19,0)$ & $14(44,0)$ & $12(37,0)$ \\
\hline O curso exigiu de você organização e dedicação frequente aos estudos. & - & $1(3,1)$ & $31(96,9)$ \\
\hline $\begin{array}{l}\text { O curso favoreceu a articulação do conhecimento teórico com atividades } \\
\text { práticas. }\end{array}$ & - & $6(19,0)$ & $26(81,0)$ \\
\hline $\begin{array}{l}\text { As atividades práticas foram suficientes para relacionar os conteúdos do } \\
\text { curso com a prática, contribuindo para sua formação profissional. }\end{array}$ & $3(9,0)$ & $15(47,0)$ & $14(44,0)$ \\
\hline $\begin{array}{l}\text { O curso propiciou acesso a conhecimentos atualizados e/ou } \\
\text { contemporâneos em sua área de formação. }\end{array}$ & - & $12(37,5)$ & $20(62,5)$ \\
\hline $\begin{array}{l}\text { O estágio supervisionado proporcionou experiências diversificadas para } \\
\text { a sua formação. }\end{array}$ & - & $(19,0)$ & $26(81,0)$ \\
\hline $\begin{array}{l}\text { As atividades realizadas durante seu trabalho de conclusão de curso } \\
\text { contribuíram para qualificar sua formação profissional }\end{array}$ & $2(6,0)$ & $8(25,0)$ & $22(69,0)$ \\
\hline $\begin{array}{l}\text { As avaliações da aprendizagem realizadas durante o curso foram } \\
\text { compatíveis com os conteúdos ou temas trabalhados pelos professores. }\end{array}$ & $1(3,0)$ & $11(34,0)$ & $20(63,0)$ \\
\hline $\begin{array}{l}\text { Os professores demonstraram domínio dos conteúdos abordados nas } \\
\text { disciplinas. }\end{array}$ & - & $4(12,5)$ & $28(87,5)$ \\
\hline $\begin{array}{l}\text { As atividades acadêmicas desenvolvidas dentro e fora da sala de aula } \\
\text { possibilitaram reflexão, convivência e respeito à diversidade*. }\end{array}$ & $1(3,0)$ & $10(31,0)$ & $20(63,0)$ \\
\hline
\end{tabular}

*1\% das respostas estava em branco ou não se aplica. 
Tabela 3. Percepção dos estudantes do curso noturno de Odontologia, de uma instituição pública em uma capital do nordeste brasileiro, no tocante à Infraestrutura-instalações físicas

\begin{tabular}{|c|c|c|c|}
\hline \multirow[b]{2}{*}{ Variáveis } & \multicolumn{3}{|c|}{ Resposta } \\
\hline & $\begin{array}{l}\text { Negativa } \\
\text { n }(\%)\end{array}$ & $\begin{array}{l}\text { Neutra } \\
\text { n }(\%)\end{array}$ & $\begin{array}{c}\text { Positiva } \\
\text { n }(\%)\end{array}$ \\
\hline $\begin{array}{l}\text { A coordenação do curso esteve disponível para orientação } \\
\text { acadêmica dos estudantes. }\end{array}$ & $4(12,5)$ & $9(28,1)$ & $19(59,4)$ \\
\hline $\begin{array}{l}\text { Os estudantes participaram de avaliações periódicas do curso } \\
\text { (disciplinas, atuação dos professores, infraestrutura). }\end{array}$ & $2(6,0)$ & $8(25,0)$ & $22(69,0)$ \\
\hline $\begin{array}{l}\text { Os professores apresentaram disponibilidade para atender os } \\
\text { estudantes fora do horário das aulas. }\end{array}$ & $2(6,0)$ & $10(31,0)$ & $20(63,0)$ \\
\hline $\begin{array}{l}\text { Os professores utilizaram tecnologias da informação e } \\
\text { comunicação (TICs) como estratégia de ensino (projetor } \\
\text { multimídia, laboratório de informática, ambiente virtual de } \\
\text { aprendizagem). }\end{array}$ & - & $6(19,0)$ & $26(81,0)$ \\
\hline $\begin{array}{l}\text { A instituição dispôs de quantidade suficiente de funcionários para } \\
\text { o apoio administrativo e acadêmico. }\end{array}$ & $1(3,1)$ & $10(31,3)$ & $21(65,6)$ \\
\hline $\begin{array}{l}\text { O curso disponibilizou monitores ou tutores para auxiliar os } \\
\text { estudantes. }\end{array}$ & - & $8(25,0)$ & $24(75,0)$ \\
\hline As condições de infraestrutura das salas de aula foram adequadas. & $2(6,3)$ & $9(28,1)$ & $21(65,6)$ \\
\hline $\begin{array}{l}\text { Os equipamentos e materiais disponíveis para as aulas práticas } \\
\text { foram adequados para a quantidade de estudantes. }\end{array}$ & $11(34,5)$ & $11(34,5)$ & $10(31,0)$ \\
\hline $\begin{array}{l}\text { Os ambientes e equipamentos destinados às aulas práticas foram } \\
\text { adequados ao curso. }\end{array}$ & $8(25,0)$ & $15(46,9)$ & $9(28,1)$ \\
\hline $\begin{array}{l}\text { A biblioteca dispôs das referências bibliográficas que os } \\
\text { estudantes necessitaram. }\end{array}$ & $1(3,1)$ & $13(40,6)$ & $18(56,3)$ \\
\hline $\begin{array}{l}\text { A instituição contou com biblioteca virtual ou conferiu acesso a } \\
\text { obras disponíveis em acervos virtuais*. }\end{array}$ & $3(9,4)$ & $8(25,0)$ & $18(56,3)$ \\
\hline $\begin{array}{l}\text { A instituição dispôs de refeitório, cantina e banheiros em } \\
\text { condições adequadas que atenderam as necessidades dos seus } \\
\text { usuários. }\end{array}$ & $6(19,0)$ & $11(34,0)$ & $15(47,0)$ \\
\hline
\end{tabular}

*9\% das respostas estavam em branco ou não se aplica.

\section{DISCUSSÃO}

A qualidade dos cursos de graduação pode ser acessada por diversos instrumentos propostos pelo Sinaes $^{8}$, onde é possível identificar que a percepção do estudante concluinte/egresso contribui para o processo de gestão do curso. A oferta do curso noturno de Odontologia, como os demais cursos desse turno, atende a uma população, em sua maioria, trabalhadora ${ }^{2,9,5}$. O perfil sociodemográfico dos alunos do curso noturno do presente estudo, incluiu um grupo na sua maioria do sexo masculino, com média de idade de 28,9 anos, solteiros e brancos. Este resultado assemelhase ao perfil de estudantes de odontologia, turno noturno, em território brasileiro, diferindo apenas quanto à predominância de sexo, já que em relação a outros cursos nacionais a predominância é do sexo feminino ${ }^{9,10}$.

O presente estudo observou uma ampla faixa de idade entre os estudantes do curso noturno (faixa etária entre 23 a 51 anos), mas que estão enquadrados especialmente na segunda década de vida, semelhante ao encontrado em outros cursos noturnos do país $2,9,10$. 
Tabela 4. Respostas dos estudantes sobre a oportunidade de ampliação da formação acadêmicaprofissional nos cursos integral e noturno de Odontologia de uma instituição pública em uma capital do nordeste brasileiro

\begin{tabular}{|c|c|c|c|}
\hline \multirow{2}{*}{ Variáveis } & \multicolumn{2}{|c|}{ Curso } & \multirow[b]{2}{*}{ p-valor } \\
\hline & Integral & Noturno & \\
\hline \multicolumn{4}{|c|}{$\begin{array}{l}\text { Foram oferecidas oportunidades para os estudantes } \\
\text { participarem de programas, projetos ou atividades de } \\
\text { extensão universitária. }\end{array}$} \\
\hline Resposta negativa & $1(1)$ & $2(6,3)$ & $0,026 *$ \\
\hline Resposta neutra & $10(11)$ & $8(25,0)$ & \\
\hline Resposta positiva & $83(88)$ & $22(68,7)$ & \\
\hline \multicolumn{4}{|c|}{$\begin{array}{l}\text { Foram oferecidas oportunidades para os estudantes } \\
\text { participarem de projetos de iniciação científica e de } \\
\text { atividades que estimularam a investigação acadêmica. }\end{array}$} \\
\hline Resposta negativa & $4(4,3)$ & $2(6,3)$ & $0,343 *$ \\
\hline Resposta neutra & $19(20,4)$ & $10(31,3)$ & \\
\hline Resposta positiva & $70(75,3)$ & $20(62,4)$ & \\
\hline \multicolumn{4}{|c|}{$\begin{array}{l}\text { O curso ofereceu condições para os estudantes participarem } \\
\text { de eventos internos elou externos à instituição. }\end{array}$} \\
\hline Resposta negativa & $6(6)$ & $2(6,3)$ & $0,917 * *$ \\
\hline Resposta neutra & $27(29)$ & $8(25,0)$ & \\
\hline Resposta positiva & $61(65)$ & $22(68,7)$ & \\
\hline \multicolumn{4}{|c|}{$\begin{array}{l}\text { A instituição ofereceu oportunidades para os estudantes } \\
\text { atuarem como representantes em órgãos colegiados. }\end{array}$} \\
\hline Resposta negativa & $12(15,4)$ & $6(20,0)$ & $0,476^{* *}$ \\
\hline Resposta neutra & $22(28,2)$ & $11(36,7)$ & \\
\hline Resposta positiva & $44(56,4)$ & $13(43,3)$ & \\
\hline \multicolumn{4}{|c|}{$\begin{array}{l}\text { Foram oferecidas oportunidades para os estudantes } \\
\text { realizarem intercâmbios elou estágios no país. }\end{array}$} \\
\hline Resposta negativa & $13(15,3)$ & $4(14,2)$ & $0,277 * *$ \\
\hline Resposta neutra & $23(27,1)$ & $12(42,9)$ & \\
\hline Resposta positiva & $49(57,6)$ & $12(42,9)$ & \\
\hline \multicolumn{4}{|c|}{$\begin{array}{l}\text { Foram oferecidas oportunidades para os estudantes } \\
\text { realizarem intercâmbios elou estágios fora do país. }\end{array}$} \\
\hline Resposta negativa & $5(5,7)$ & $3(9,6)$ & $\mathbf{0 , 0 4 9} * *$ \\
\hline Resposta neutra & $21(24,1)$ & $14(45,2)$ & \\
\hline Resposta positiva & $61(70,2)$ & $14(45,2)$ & \\
\hline \multicolumn{4}{|c|}{$\begin{array}{l}\text { A instituição promoveu atividades de cultura, de lazer e de } \\
\text { interação social. }\end{array}$} \\
\hline Resposta negativa & $14(15,6)$ & $8(25,8)$ & $0,368^{*}$ \\
\hline Resposta neutra & $32(35,6)$ & $8(25,8)$ & \\
\hline Resposta positiva & $44(48,8)$ & $15(48,4)$ & \\
\hline
\end{tabular}

* Teste Exato de Fisher; ** Teste Qui-Quadrado

O curso de Odontologia está no grupo dos cursos ditos elitizados no cenário brasileiro, com renda familiar per capita muito acima do que ganha a maioria da população brasileira ${ }^{11}$. Segundo o Instituto Brasileiro de Geografia e
Estatística (IBGE), a renda domiciliar per capita no Brasil era $\mathrm{R} \$ 1.373,00$ em $2018^{12}$. Embora a maioria dos estudantes do curso se enquadrem nesse perfil, 40,6\% dos alunos do curso noturno possuem renda familiar total de 1,5 a 3 salários 
mínimos. Características como menor prevalência do sexo feminino, idade mais avançada, e baixa condição socioeconômica estão entre os achados para estudantes do curso noturno em pesquisa realizada na Faculdade de Odontologia da Universidade Estadual Paulista "Júlio de Mesquita Filho (UNESP) de São José dos Campos, onde os autores traçaram diferenças nos perfis dos estudantes dos cursos diurno e noturno da instituição ${ }^{13}$.

Segundo dados do INEP, ${ }^{6} 76,6 \%$ dos estudantes do curso diurno da instituição em estudo cursaram o ensino básico em escola privada. Este fato reforça estudo que relaciona um maior percentual de alunos de escolas privadas a uma maior atratividade por profissões que possuem um melhor retorno econômico como cursos de Medicina, Odontologia e Engenharia ${ }^{11}$. No entanto, no curso noturno da mesma instituição, $43,8 \%$ dos estudantes cursaram todo ensino médio em escola pública e $34,4 \%$ deles ingressaram na universidade por meio de políticas afirmativas ou de inclusão social, por terem estudado em escola pública, ou em escola particular como bolsista. De acordo com a literatura este é o critério mais frequentemente utilizado por alunos da escola pública para o acesso às universidades públicas do país ${ }^{14}$.

A lei das cotas abriu importantes espaços para estudantes das escolas públicas e para os grupos sociais menos representados. Segundo pesquisa que avalia os três primeiros ciclos do Enade, o percentual de alunos de escola pública nas universidades públicas do país passou de $46 \%$ no primeiro ciclo, para $60 \%$ no terceiro ciclo do exame ${ }^{15}$.

Em relação à escolaridade dos pais, a amostra foi composta majoritariamente por aqueles que não possuem diploma universitário. É possível observar no Brasil a diminuição gradativa de filhos de pais com escolaridade superior em todos os cursos. No curso de Odontologia, esse número passou de $53 \%$ para $31 \%$ entre os anos de 1991 e 2012, o que indica que as classes menos favorecidas economicamente começam a ter mais oportunidade de acesso às universidades públicas, em nível nacional ${ }^{15}$.

A presente análise apontou que 37,5\% dos estudantes do curso noturno possuem vínculo empregatício com carga horária de 20 horas ou mais de trabalho. Esta mudança no perfil dos acadêmicos é observada em estudos realizados em outras universidades brasileiras, de uma maneira ainda mais significativa que no presente estudo, no qual os estudantes trabalhadores do curso noturno chegam a mais de $50 \%$, com carga horária de trabalho de até 40 horas semanais $2,9,5$.

Essa pesquisa indicou que $59,4 \%$ dos alunos afirmaram dedicar quatro ou mais horas por semana aos seus estudos. Isso pode estar relacionado ao fato de $62,5 \%$ não possuírem vínculo empregatício e poderem se dedicar exclusivamente aos estudos, diferentemente de outros cursos noturnos nacionais onde a maioria dos alunos do curso noturno trabalham $\mathrm{e}$ possuem menor tempo de dedicação aos estudos $2,9,5$.

De maneira geral, a percepção dos alunos do curso de Odontologia noturno da instituição onde foi realizada a pesquisa foi positiva quanto à organização didático/pedagógica do curso e quanto à infraestrutura/instalações físicas. Esses fatores são reconhecidos como motivadores na frequência dos alunos à escola ${ }^{16}$.

Menos de $50 \%$ da amostra considerou suficiente a quantidade de aulas práticas do curso. A falta de aulas ou atividades práticas também é citada como insatisfatória por estudantes de outros cursos de Odontologia no território brasileiro, refletindo na insegurança no tocante à realização do atendimento odontológico integral e de boa qualidade ${ }^{13,17}$. 
Uma menor parte dos estudantes tiveram a percepção positiva quanto às oportunidades de superação das dificuldades relacionadas ao processo de formação profissional. A persistência dessas dificuldades pode ser relacionada ao abandono do curso. Em razão de achados semelhantes terem sido identificados, foi proposto pelo Curso de Graduação em Pedagogia da Universidade Federal do Ceará (UFC), uma ampla discussão sobre a necessidade de criar-se uma coordenação para o curso noturno, fato este que possibilitaria melhor atendimento aos discentes desse turno específico. Outro ponto identificado para ser amadurecido e discutido no âmbito interno das coordenações dos cursos de graduação da UFC foi a necessidade de haver um acompanhamento sistemático dos universitários recém-ingressos ${ }^{18}$.

No relatório de desempenho do curso de Odontologia da IES analisada observou-se a insatisfação dos estudantes quanto aos ambientes e equipamentos destinados às aulas práticas e a insuficiência de equipamentos e materiais disponíveis para contemplar todos os alunos. Tal percepção é semelhante para os estudantes do curso diurno e noturno da instituição, indicando que a insatisfação está relacionada ao curso de uma maneira geral, não apenas a um turno em especial ${ }^{6}$.

Outra variável que mostra insatisfação dos discentes em relação a infraestrutura/instalações físicas da instituição referia-se à disponibilidade de refeitório, cantina e banheiros em condições adequadas. Esses são serviços ditos essenciais para a permanência de alunos e professores na instituição, ou seja, para a motivação de discentes e docentes a frequentar a escola, além de estarem relacionados ao desempenho acadêmico ${ }^{1,5,16-18}$.

$\mathrm{O}$ presente estudo apresentou diferença significativa nos indicadores de internacionalização e extensão na seção do questionário do estudante quando comparado ao curso da mesma IES, no turno integral. A proposta da política de ampliação do ensino superior para o turno noturno segue fragmentada no que se refere à oportunidade de aprendizagem complementar nas universidades públicas ${ }^{1}$. Há uma baixa oferta de atividades extracurriculares para os estudantes do curso noturno, no horário em que eles estão na faculdade, restringindo a sua participação em atividades complementares para a formação profissional ${ }^{5,18}$.

O sistema de educação superior no Brasil está estruturado, sobretudo, para contemplar o estudante em tempo integral. Acolher a proposta de cursos no período noturno é desafiador em relação às condições ofertadas a este estudante, que depois de uma jornada de trabalho vai em busca da aquisição de conhecimentos, de formação profissional e de um diploma de curso superior ${ }^{17}$.

\section{CONCLUSÕES}

O presente estudo aponta que, de uma forma geral, a percepção dos egressos do curso de Odontologia noturno da IES pública situada no Nordeste do Brasil, no ENADE 2016, expressou resultados positivos, permitindo inferir critério de qualidade. No entanto, foi constatada diferença significativa nos indicadores de internacionalização e extensão na seção do questionário do estudante quando comparado com o curso em período integral da mesma IES, sugerindo fragilidade na formação e na articulação entre os pilares ensino, pesquisa e extensão, que definem o papel das instituições de ensino superior brasileiras junto à sociedade.

\section{ABSTRACT \\ Perception of graduates about the quality of the night course in dentistry at a public institution in northeastern Brazil}

This was a documentary research, using data from the student questionnaire of ENADE 2016. We analyzed the answers given by students who 
completed a public higher education course in Dentistry at a public institution in a Capital city in Northeastern Brazil. The IES data were filtered from the ENADE 2016 microdata worksheet, using the IES code, as obtained from the electronic system of the MEC (eMEC). The sociodemographic variables were used to characterize the profile of the graduates of the night course. The answers to the questionnaire were grouped into categories of positive, neutral or negative responses, for the three sections of the questionnaire: didactic-pedagogical organization, infrastructure and physical facilities of the course, and expansion of academic and professional development. The latter was analyzed comparatively between the night course(?)and full-time students of the same IEH, by using the Chi-square tests and Fisher's exact test applied with $95 \%$ confidence. The sociodemographic profile included a group of single, white, males, with a mean age of 28.9 years. In the Quality assessment of the didacticpedagogical organization, physical infrastructure and facilities of the course, students' perceptions were positive for the majority of the subcomponents of the questionnaire. There was statistically significant difference between the night and full-time course students' responses, in terms of opportunities for extension and exchanges and / or international internship. The perception of the graduates, presented positive results, conferring a criterion of quality. The study indicated that the policy of expansion of higher education to include the night classes remained fragmented as extracurricular activities in the development of these (night) students at the public university.

Descriptors: Education, Dental. Education, Higher. Educational Measurement.

\section{REFERÊNCIAS}

1. Maranhão JD, Veras RM. O ensino noturno na Universidade Federal da Bahia: percepções dos estudantes. Ensaio: Aval Pol Públ Educ. 2017; 25(96):553-84.

2. Lamers JMS, Souza MG, Toassi, RFC. Democratização do acesso à educação superior pública a partir do REUNI: o curso noturno de Odontologia da Universidade Federal do Rio Grande do Sul. Criar Educação. 2015; 4(1):1-21.

3. Brasil. Ministério da Educação. REUNI Reestruturação e Expansão das Universidades Federais. Diretrizes Gerais. Plano de Desenvolvimento da Educação. Documento elaborado pelo Grupo Assessor nomeado pela Portaria $\mathrm{n}^{\mathrm{o}} 552 \mathrm{Sesu} / \mathrm{MEC}$, de 25 de junho de 2007 , em complemento ao art. $1^{\circ} \S 2^{\circ}$ do Decreto Presidencial $n^{\circ}$ 6.096, de 24 de abril de 2007. Agosto 2007. [Acesso em 12 jun. 2018]. Disponível em: http://www.ufcg. edu.br/prt_ufcg/reuni/diretrizes_gerais.pdf.

4. Lamers JMS, Santos BS, Toassi RFC. Retenção e evasão no Ensino Superior público: estudo de caso em um curso noturno de Odontologia. Educ Rev. 2017; 33:e154730.

5. BRASIL. Ministério da Educação (MEC). Instituto Nacional de Estudos e Pesquisas Educacionais Anísio Teixeira. (INEP). Sinaes. MEC/Inep. [Acesso em 12 jun. 2018]. Disponível em: http://inep.gov.br/sinaes.

6. Gontijo FBS. Análise dos relatórios Enade em um curso de Pedagogia: Impressões sobre a prova e questionários socioeconômicos nos anos 2005, 2008 e 2011. [Acesso em 12 jun. 2018]. Disponível em: https://www. aforges.org/wp-content/uploads/2016/11/37Simone-Gontijo_Ana_lise-dos-relato_riosEnade.pdf.

7. Souza JM. Trajetória do estudante no curso noturno de Odontologia da Universidade Federal do Rio Grande do Sul: perfil do ingressante, situação acadêmica e motivos de retenção e evasão [tese]. Porto Alegre: Universidade Federal do Rio Grande do Sul; 2014.

8. Loffredo LCM, Pinelli C, Garcia PPNS, Scaf G, Camparis CM. Característica Socioeconômica, Cultural e Familiar de 
Estudantes de Odontologia. Rev Odontol UNESP. 2004; 33(4):175-82.

9. Marcelino J, Pinto R. O acesso à educação superior no Brasil. Rev Educ Soc. 2004; 25 (88):727-56.

10. Amorim D. Economia. Exame. 27 de fev. 2019. [Acesso em 12 jun. 2018]. Disponível em: https://exame.abril.com.br/economia/ ibge-renda-domiciliar-per-capita-no-brasilfoi-de-r-1-373-em-2018/.

11. Junqueira JC, Colombo CED, Tavares, PG, Rocha RFD, Carvalho YR, Rodrigues JR. Quem é e o que pensa o graduando de odontologia. Rev Odontol UNESP. 2013; 31(2):269-84.

12. Oliveira ASR, Silva IR. Políticas de inclusão social no ensino superior brasileiro: um estudo sobre o perfil socioeconômico de estudantes nos anos 2010 a 2012. Educ Rev. 2017; 33 (6): 2-28.

13. Ristoff D. O novo perfil do campus brasileiro: uma análise do perfil socioeconômico do estudante de graduação. Avaliação. 2014; 19(3):723-47.

14. Filho AT, Quaglio P. Cenário urbano para o estudante do ensino superior noturno na cidade de São Paulo: triste realidade ou palco de heróis? Millenium. 2005; 31(10):74-87.
15. Souza SA, Reinert JN. Avaliação de um curso de ensino superior através da satisfação/ insatisfação discente. Avaliação. 2010; 15(1): 159-76.

16. Boff BC, Booth IAS, Martins JA, Villas-boas V. Núcleos de Apoio ao Ensino de Engenharia: Superando dificuldades para prevenir Evasão. In Anais: XLII Congresso Brasileiro de Educação em Engenharia. Juiz de Fora: UFJF.2014; 4: 1-11.

17. Filho AT. Ensino superior noturno no Brasil: as dificuldades do entorno educacional e a importância do relacionamento social no ambiente educacional. Rev Educ UFSM. 2004; 29(1):21-36.

18. Bandeira AW, Cristiany GA. Avaliação da qualidade educacional da Faculdade de Educação (FACED) da Universidade Federal do Ceará (UFC). Ensaio: Aval Pol Públ Educ. 2009; 17(62):153-68.

\section{Correspondência para:}

Gustavo Pina Godoy e-mail: gruiga@ hotmail.com

Av. Prof. Moraes Rego 1235

Cidade Universitária

50670-901 Recife/PE 